\title{
Biosimilar epoetin for the management of chemotherapy-induced anemia in elderly patients
}

\author{
This article was published in the following Dove Press journal: \\ OncoTargets and Therapy \\ 28 October 2016 \\ Number of times this article has been viewed
}

\author{
Jean-Emmanuel Kurtz' \\ Pierre Soubeyran ${ }^{2}$ \\ Mauricette Michallet ${ }^{3}$ \\ Elisabeth Luporsi ${ }^{4}$ \\ Hélène Albrand ${ }^{5}$ \\ 'Department of Oncology and \\ Hematology, Hôpitaux Universitaires \\ de Strasbourg, Strasbourg, \\ ${ }^{2}$ Department of Medical Oncology, \\ Institut Bergonié and Université de \\ Bordeaux, Bordeaux, ${ }^{3}$ Department of \\ Hematology, Lyon-Sud Hospital, Lyon, \\ ${ }^{4}$ Institut de Cancérologie de Lorraine \\ Alexis Vautrin, Nancy, ${ }^{5}$ Laboratoire \\ Hospira France, Paris, France
}

Correspondence: Jean-Emmanuel Kurtz Hôpitaux Universitaires de Strasbourg, I Av Molière, Strasbourg 67000, France Email j-emmanuel.kurtz@chru-strasbourg.fr
Introduction: Chemotherapy-induced anemia (CIA) is a frequent complication among cancer patients, with elderly patients more likely to suffer severe effects. Biosimilar erythropoiesisstimulating agents lower costs of supportive cancer treatment, and thus are particularly relevant in the elderly cancer population, which is growing rapidly worldwide. The goal of this subanalysis was to compare the tolerability and effectiveness of an epoetin biosimilar for treating CIA in patients $<70$ years old vs patients $\geq 70$ years old.

Materials and methods: The ORHEO observational trial enrolled patients with CIA (hemoglobin $[\mathrm{Hb}]<11 \mathrm{~g} / \mathrm{dL}$ ) in association with chemotherapy for solid tumors, lymphoma, or myeloma. Patients received an epoetin biosimilar and were evaluated at 3 and 6 months for response, defined as achieving target $\mathrm{Hb}$ without blood transfusions during the 3 weeks preceding measurement, $\mathrm{Hb} \geq 10 \mathrm{~g} / \mathrm{dL}$, or $\mathrm{Hb}$ increase $\geq 1 \mathrm{~g} / \mathrm{dL}$ since study enrollment. Secondary end points included changes in $\mathrm{Hb}$ level, treatment interruptions, transfusion rates, and adverse events.

Results: Among the 2,310 original patients, 1,301 <70 years old were compared to $1,009 \geq 70$ years old. Almost all patients $(99.9 \%)$ received the biosimilar epoetin zeta (Retacrit). Patients in both groups responded well to treatment with biosimilar epoetin, with $79.8 \%$ and $84 \%$ responding at 3 months and $86.3 \%$ and $86.8 \%$ at 6 months among younger and elderly cohorts, respectively. Biosimilar epoetin therapy was well tolerated, with adverse events reported in only $17.6 \%$ and $16.4 \%$ of younger and elderly patients, respectively. A greater number of thromboembolic events and a lesser rate of infections were reported in the elderly, but were still lower than reported in clinical registration trials. No treatment fatalities occurred in either group.

Conclusion: Biosimilar epoetin was an effective and well-tolerated treatment for managing CIA in elderly cancer patients.

Keywords: biosimilar, elderly, epoetin, ESA, chemotherapy-induced anemia, anemia

\section{Introduction}

Erythropoiesis-stimulating agents (ESAs) are human recombinant forms of erythropoietin that stimulate bone marrow to produce red blood cells. ${ }^{1}$ In addition to alleviating the symptoms of anemia, the use of ESAs may prevent the need for red blood-cell transfusions in patients with chemotherapy-induced anemia $(\mathrm{CIA})^{2}$ and avoid transfusion-related complications. ${ }^{3,4}$

CIA is estimated to affect as many as $67 \%$ of patients undergoing myelosuppressive chemotherapy. ${ }^{5}$ In addition to affecting patient quality of life adversely, ${ }^{6}$ CIA has been associated with reduced survival rates for patients with solid tumors, lymphoma, or myeloma. ${ }^{7}$ The incidence of anemia rises with age, with some research reporting a notable increase in prevalence of anemia in the oldest subjects. ${ }^{8}$ In the elderly, CIA is associated with more severe symptoms, ranging from weakness and 
fatigue to increased falls and depression. Although CIA is of major concern when treating the elderly patient, there is a paucity of information systematically addressing the clinical response of ESAs in elderly with CIA.

Since the patent expiration of the first ESA - epoetin alfa - several biosimilar epoetin options have become available. ${ }^{9}$ Although the quality, safety, and clinical efficacy of biosimilar products have been established through rigorous preapproval testing, clinical and postapproval assessments ensuring similarity of safety and efficacy to originator products are recommended. ${ }^{10,11}$ The approval of epoetin biosimilars in the European Union requires postmarketing studies. The ORHEO study was an observational, longitudinal, multicenter study performed in France to evaluate the efficacy and safety of biosimilar epoetins for the treatment of CIA in the clinical setting. ${ }^{12}$

For the reasons presented regarding the importance of managing CIA in the elderly patient and the lack of studies, an exploratory subanalysis was performed on the results of the ORHEO observational study ${ }^{12}$ to compare the tolerability and effectiveness of epoetin biosimilars in the management of CIA in younger patients ( $<70$ years old) versus elderly patients ( $\geq 70$ years old). A description of the ORHEO trial is presented in the following sections.

\section{Materials and methods}

ORHEO was a large observational, noninterventional, longitudinal, national, multicenter study (NCT02140736). ${ }^{12}$ Inclusion criteria included patients at least 18 years of age presenting with CIA (irrespective of chemotherapy cycle) associated with solid tumors, lymphomas, or myelomas and eligible for treatment with an epoetin alfa biosimilar. Patient characteristics were recorded at baseline, along with anemia-related information, such as observed and target hemoglobin $(\mathrm{Hb}$; as chosen by the treating clinician), blood count, and iron-load profile; brand and dose of epoetin biosimilar prescribed; details of any other treatments; and adverse events. Patients were followed for 6 months over three visits: inclusion visit, 3-month follow-up visit, and 6-month end-of-study visit. Informed patient consent was obtained verbally prior to participation in the study. The study was reviewed and approved by the ethics committee (Advisory Committee on Information Processing Research in the Field of Health [Comité consultatif sur le traitement de l'information en matière de recherche dans le domaine de la santé], Ministry of Higher Education and Research, INSERM 700, Faculty of Medicine, Paris, France).

\section{Statistical methodology}

All statistical analyses were performed on the per protocol population. This excluded patients with missing baseline $\mathrm{Hb}$ values, patients for whom age was not recorded, patients who had not initiated chemotherapy at baseline, patients who were not receiving an epoetin biosimilar at baseline, and patients who switched to another epoetin treatment between baseline and month 6 . In addition, patients with a disease other than those described in the protocol were excluded. The rates of $\mathrm{Hb}$ responders were calculated at each visit with $95 \%$ confidence intervals using SAS software (9.2 release).

\section{Primary and secondary objectives of the ORHEO study}

The primary objective of the ORHEO study was to observe response to treatment with an epoetin alfa biosimilar in patients presenting with CIA in association with solid tumors, lymphoma, or myeloma. Secondary objectives included changes in biological indicators, such as $\mathrm{Hb}$, hematocrit, reticulocytes, serum iron, ferritin, and blood pressure, disease outcome, and the safety profile of epoetin alfa biosimilars.

CIA was defined according to World Health Organization (WHO) criteria, ${ }^{13}$ measured prior to starting treatment. A patient was described as a "responder" to treatment with an epoetin biosimilar if $\mathrm{Hb}$ levels were at least equal to $10 \mathrm{~g} / \mathrm{dL}$, if there had been an increase in Hb levels of at least $1 \mathrm{~g} / \mathrm{dL}$ since the inclusion visit, or if $\mathrm{Hb}$ reached the target level set by the physician on day 0 , without any blood transfusions in the 3 weeks prior to measurement (transfusion details were reported by investigators). In patients with baseline $\mathrm{Hb}$ levels at least equal to $10 \mathrm{~g} / \mathrm{dL}$, only those who reached their $\mathrm{Hb}$ target or had an $\mathrm{Hb}$ increase $>1 \mathrm{~g} / \mathrm{dL}$ were regarded as responders. Disease outcomes were reported using the WHO performance score. ${ }^{14}$

In total, ORHEO enrolled 2,333 patients from 235 centers; of these, 2,310 patients were included in the analysis. ${ }^{12}$ At baseline, $2.2 \%$ of patients had grade 0 anemia $(\mathrm{Hb} \geq 11 \mathrm{~g} / \mathrm{dL}), 57.9 \%$ had grade 1 anemia $(\mathrm{Hb} 9.5-11 \mathrm{~g} / \mathrm{dL})$, $35.6 \%$ had grade 2 anemia ( $\mathrm{Hb} 8-9.5 \mathrm{~g} / \mathrm{dL}$ ), $4 \%$ had grade 3 (severe) anemia ( $\mathrm{Hb} 6.5-8 \mathrm{~g} / \mathrm{dL}$ ), and $0.3 \%$ had grade 4 (very severe) anemia $(\mathrm{Hb}<6.5 \mathrm{~g} / \mathrm{dL})$. $\mathrm{Hb}$ response was achieved in $81.6 \%$ and $86.5 \%$ of patients at 3 and 6 months, respectively. Overall mean ( \pm standard deviation) change in $\mathrm{Hb}$ level was $1.52 \pm 1.61 \mathrm{~g} / \mathrm{dL}$ and $1.72 \pm 1.61 \mathrm{~g} / \mathrm{dL}$ at 3 and 6 months, respectively.

Almost all patients (99.9\%) received the biosimilar epoetin zeta (Retacrit; Hospira, Lake Forest, IL, USA), while three patients received epoetin alfa (Binocrit; Sandoz, 
Holzkirchen, Germany). The median dose of biosimilar epoetin was 30,000 IU/week during the course of the study. Most patients (99.7\%) received biosimilar epoetin via the subcutaneous route, and almost all (98\%) received single weekly biosimilar epoetin injections.

\section{Results}

\section{Use in patients $<70$ years old vs patients $\geq 70$ years old}

\section{Baseline characteristics}

Among the original 2,310 patients, 1,301 (49.2\% male $)<70$ years old were compared to 1,009 patients $(54.3 \%$ male) $\geq 70$ years old. The overall baseline characteristics of the two groups were very similar (Table 1). The median age was 60 years (range 18-69 years) and 77 years (range $70-93$ years) (Figure 1) in the younger and elderly populations, respectively. The distribution of patients across tumor types was similar for both groups, except for a greater number of patients with myeloma in the elderly group at 6 months $(P=0.052)$. There was no difference in mean $\mathrm{Hb}$ levels at 3 and 6 months. At study entry, grade 2 anemia was similar in the younger patients (36.5\%) vs elderly (34.4\%). Iron supplementation was administered somewhat less in the elderly cohort (25.9\% vs $27.2 \%)$, with a similar percentage of patients in both groups receiving iron intravenously (9.9\% vs $10.6 \%)$.

\section{Primary end point}

Patients in both groups responded well to treatment with biosimilar epoetin. The overall response was significantly greater among the elderly group at 3 months (84\% vs $79.8 \%$; $P=0.0181)$, with a significantly greater solid-tumor response ( $84 \%$ vs $79.5 \% ; P=0.026$ ) (Table 2 ). At 6 months, there were no differences in overall response rates.

Table I Baseline patient characteristics

\begin{tabular}{lll}
\hline & $\begin{array}{l}<\mathbf{7 0} \text { years old } \\
(\mathbf{n}=\mathbf{I}, \mathbf{3 0} \mathrm{I})\end{array}$ & $\begin{array}{l}\geq \mathbf{7 0} \text { years old } \\
(\mathbf{n}=\mathbf{I}, \mathbf{0 0 9})\end{array}$ \\
\hline $\begin{array}{l}\text { Median age, years (range) } \\
\text { Male sex (\%) }\end{array}$ & $60(18-69)$ & $77(70-93)$ \\
$\begin{array}{l}\text { Malignancy type, } \mathrm{n}(\%) \\
\quad \text { Solid tumors }\end{array}$ & 54.3 \\
$\quad$ Lymphoma & $1,089(83.7)$ & $749(74.2)$ \\
$\quad$ Myeloma & $138(10.6)$ & $163(16.2)$ \\
WHO performance status (\%) & $74(5.7)$ & $97(9.6)$ \\
0 & 24.3 & \\
I & 52.1 & 16.3 \\
$\geq 2$ & 23.6 & 52.3 \\
Anemia severity (\%) & & 31.4 \\
$\quad$ Grade I & 56.6 & 59.7 \\
Grade 2 & 36.5 & 34.4 \\
\hline
\end{tabular}

Abbreviation: WHO, World Health Organization.

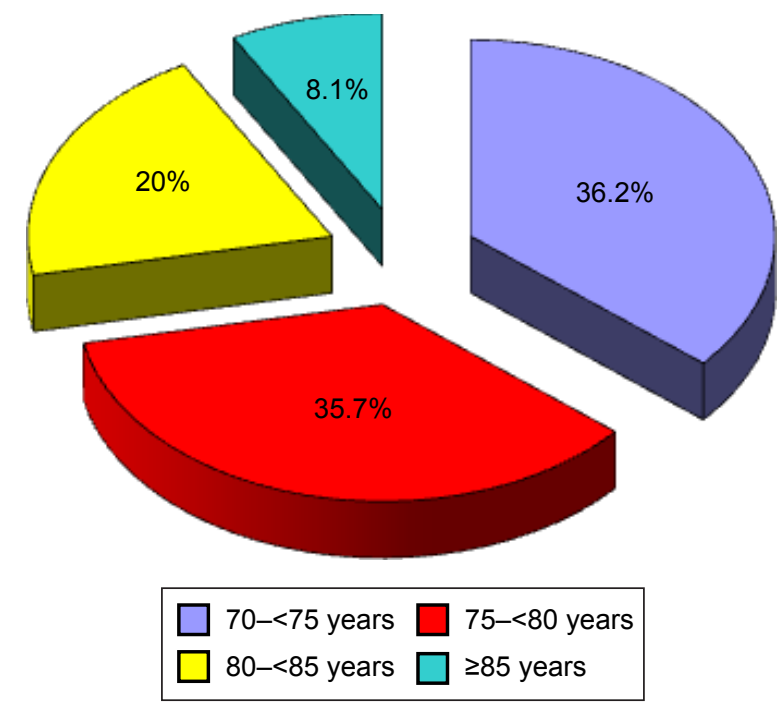

Figure I Breakdown by age in the $\geq 70$-year age-group.

\section{Secondary end points}

Transfusion rates were $10.6 \%$ and $7.9 \%$ at 3 months and $6.4 \%$ and $4.9 \%$ at 6 months in younger and elderly patients, respectively. The safety profile of biosimilar epoetin was similar in both groups. Biosimilar epoetin therapy was well tolerated, with adverse events reported in only $17.6 \%$ and $16.4 \%$ of younger and elderly patients, respectively (Table 3 ). However, thromboembolic events occurred with significantly greater frequency among the older patients (4.5\% vs $2.7 \%$, $P=0.011$ ), while infections occurred with significantly greater frequency among younger patients $(6.6 \%$ vs $3 \%, P=0.0002)$. Numbers were small, and the incidence of thrombosis was still less than that reported in the clinical epoetin registration trials. ${ }^{15}$ Adverse events experienced in the elderly group are shown by specific disease state in Figure 2. No treatmentrelated fatalities occurred in any group. At 3 months, 26.1\% and $32.5 \%$ of elderly and younger patients had discontinued biosimilar epoetin, respectively, and $21 \%$ and $17.1 \%$ of elderly and younger patients had a transient interruption in

Table 2 Response rates

\begin{tabular}{llll}
\hline & $<\mathbf{7 0}$ years old & $\geq \mathbf{7 0}$ years old & $P$-value \\
\hline 3 months & & & \\
Overall response & $79.8 \%$ & $84 \%$ & $P=0.0181$ \\
Lymphoma & $77.1 \%$ & $84 \%$ & $P=0.2$ \\
Myeloma & $88.9 \%$ & $83.9 \%$ & $P=0.50$ \\
Solid tumors & $79.5 \%$ & $84 \%$ & $P=0.026$ \\
6 months & & & \\
Overall response & $86.3 \%$ & $86.8 \%$ & $P=0.82$ \\
Lymphoma & $81.9 \%$ & $90 \%$ & $P=0.11$ \\
Myeloma & $84.9 \%$ & $81.5 \%$ & $P=0.75$ \\
Solid tumors & $87.1 \%$ & $86.9 \%$ & $P=0.99$ \\
\hline
\end{tabular}


Table 3 Clinically significant adverse events

\begin{tabular}{lll}
\hline & $<\mathbf{7 0}$ years old, \% & $\geq \mathbf{7 0}$ years old, \% \\
\hline Total $^{\mathrm{a}}$ & 17.6 & 16.4 \\
Thromboembolic events $^{\mathrm{b}}$ & 2.7 & 4.5 \\
Infection $^{\mathrm{c}}$ & 6.6 & 3 \\
Increased blood pressure & 2.1 & 2.5 \\
Bleeding & 2.9 & 1.7 \\
Influenza-like symptoms & $\mathrm{I} .5$ & $\mathrm{I}$ \\
Injection-site reaction & $\mathrm{I} .4$ & 0.8 \\
Rash & $\mathrm{I} .1$ & 0.6 \\
Other & 8.4 & 9.6 \\
\hline
\end{tabular}

Notes: aMore than one adverse event may have been reported in individual patients; ${ }^{b} P=0.01 \mathrm{I} ;{ }^{c} P=0.0002$.

biosimilar epoetin treatment. The most common reason for permanent and transient discontinuations in both groups was achieving $\mathrm{Hb}$ target level. Overall, there were more early withdrawals from the study among patients $\geq 70$ years old (25.76\% vs $29.44 \%, P=0.0537)$.

\section{Discussion}

Incidence rates for all cancers combined have increased for all age-groups since the mid-1970s, with the largest increase in the $75+$-year age-group, increasing by $44 \%$ between 1975-1977 and 2009-2011. ${ }^{16}$ Although biosimilar studies in the elderly population are rare, there is particular relevance, due to the propensity for biosimilar ESAs to lower overall costs of cancer treatment. Pharmacoeconomic studies suggest that the availability of a biosimilar may result in significant savings due to two factors: the lower price of the biosimilar and the potential subsequent price reduction for the originator product. ${ }^{17,18}$ The financial savings realized from supportivecare budgets can be used to expand access to expensive but

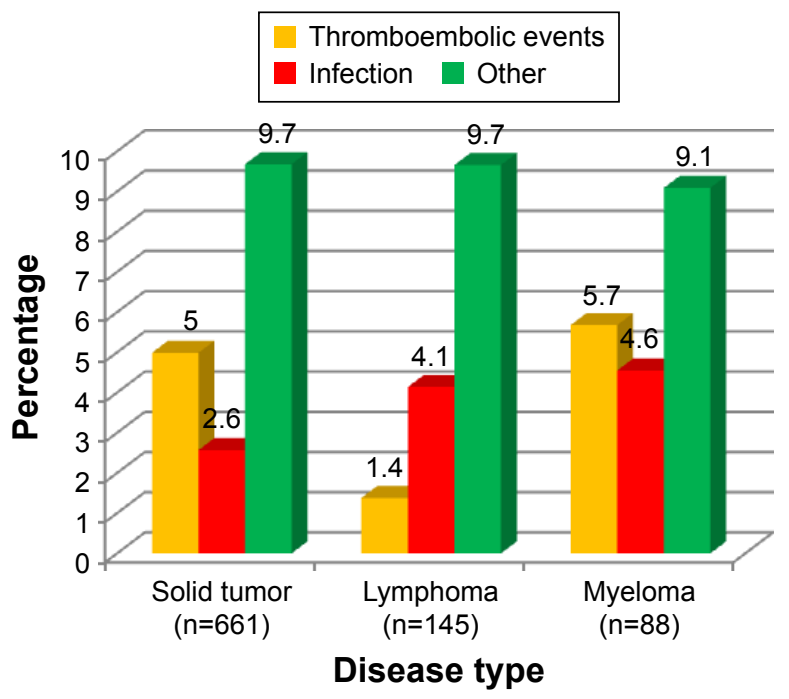

Figure 2 Percentage of patients in the $\geq 70$-year age-group who experienced main adverse events by disease type. potentially life-saving anticancer therapies. ${ }^{17,19}$ Additionally, use of biosimilar ESAs can provide savings in hospital budgets, expand access to ESA treatment, and provide physicians with the opportunity to treat anemia earlier. ${ }^{17,19}$

This subanalysis was designed to assess the clinical profile of biosimilar epoetin as part of an ongoing commitment to postmarketing observation. The results demonstrated that biosimilar epoetin is as effective in elderly patients as in younger patients. Safety profiles were similar, except for a higher incidence of thromboembolic events and a lower frequency of infections among the older patients; however, numbers were small. ${ }^{15}$ There was no evidence of unexpected treatment-related adverse events. Due to the methodology design of an observational trial, no samples for analysis of antibodies to erythropoietin receptors were collected. The results of this subanalysis support previous research on the effectiveness and tolerability of biosimilar epoetin in treating patients with CIA. ${ }^{20}$

The strengths of this study include the following: 1) data specifically evaluating the safety and effectiveness of biosimilar epoetin in the elderly are lacking, 2) this subanalysis involved a large number of patients, 3) the methods were as close to current, "real-life" conditions as possible, and 4) it is unlikely that future observational studies will focus on the elderly population. The limitations of this subanalysis include: 1) the inherent weakness of observational studies compared to controlled randomized trials, such as severity grading of adverse events, 2) other possible causes of anemia undiagnosed, and 3) the lack of geriatric assessment data, such as activities of daily living and instrumental activities of daily living that were not end points of the ORHEO study.

Future trials evaluating all epoetin use (biosimilar and reference) in the elderly are warranted. Ideally, these trials should investigate the effect and management of iron load in the patient, as epoetins are not optimally effective in patients with iron deficiency. Despite important efforts toward prescribers, there is still a consistent lack of management of iron deficiency. This must be emphasized in the geriatric population, in which the prevalence of iron deficiency likely may be underdiagnosed. Therefore, the current analysis also supports the need for general practitioners' as well as specialists' education toward exploring iron load prior to initiating therapy with epoetin, and in cases of iron deficiency, appropriate iron reloading.

\section{Conclusion}

This study assessed the clinical profile of biosimilar epoetin as part of an ongoing commitment to postmarketing observation, and demonstrated that biosimilar epoetin is 
well tolerated and efficacious in treating anemia in elderly patients with CIA. Although there was an increased incidence of thromboembolic events in the elderly population, numbers were small, and there were no fatalities or pulmonary embolisms. Overall, these data, together with the observed adverse consequences of anemia in the elderly, are major arguments that should be considered by physicians to better implement the use of biosimilar ESAs in older patients with cancer.

Observational studies present a valuable means of assessing efficacy and safety under clinical conditions, and complement the current body of data derived from randomized controlled trials. Because of the favorable cost differential, the authors suggest that further observational trials be conducted that specifically analyze the efficacy, safety, and tolerability of biosimilars in the elderly.

\section{Acknowledgments}

Assistance with data analysis was provided by Karine Andre (Clinact), funded by Hospira Ltd. Medical writing and editorial support was provided by Anne Gentry, PharmD (Gentry Medical Communications LLC), funded by Hospira Inc, a Pfizer company. This study was funded by Hospira SAS France, which was acquired by Pfizer in September 2015. The abstract of this paper was presented at the 2013 SIOG Conference in Copenhagen, Denmark as a poster presentation. The poster abstract was published in the Journal of Geriatric Oncology (2013;4 Suppl 1:S82).

\section{Disclosure}

JEK has served on speakers' bureaux for MSD Ltd, Pharmamar, and Roche, and PS on speakers' bureaux for Teva, Spectrum Pharm Inc, Celgene, and Hospira Ltd. HA was an employee of Hospira, a Pfizer company while the trial was conducted. The other authors report no conflicts of interest in this work.

\section{References}

1. Macdougall IC. Novel erythropoiesis-stimulating agents: a new era in anemia management. Clin J Am Soc Nephrol. 2008;3:200-207.

2. Aapro MS. Anemia management with erythropoiesis-stimulating agents: a risk-benefit update. Oncologist. 2008;13 Suppl 3:1-3.

3. Stramer SL. Current risks of transfusion-transmitted agents: a review. Arch Pathol Lab Med. 2007;131:702-707.

OncoTargets and Therapy

\section{Publish your work in this journal}

OncoTargets and Therapy is an international, peer-reviewed, open access journal focusing on the pathological basis of all cancers, potential targets for therapy and treatment protocols employed to improve the management of cancer patients. The journal also focuses on the impact of management programs and new therapeutic agents and protocols on
4. Bernard AC, Davenport DL, Chang PK, Vaughan TB, Zwischenberger JB. Intraoperative transfusion of $1 \mathrm{U}$ to $2 \mathrm{U}$ packed red blood cells is associated with increased 30-day mortality, surgical-site infection, pneumonia, and sepsis in general surgery patients. J Am Coll Surg. 2009;208:931-937.

5. Ludwig H, Van Belle S, Barrett-Lee P, et al. The European Cancer Anemia Survey (ECAS): a large, multinational, prospective survey defining the prevalence, incidence, and treatment of anaemia in cancer patients. Eur J Cancer. 2004;40:2293-2306.

6. Cella D, Kallich J, McDermott A, Xu X. The longitudinal relationship of hemoglobin, fatigue and quality of life in anemic cancer patients: results from five randomized clinical trials. Ann Oncol. 2004;15:979-986.

7. Caro JJ, Salas M, Ward A, Goss G. Anemia as an independent prognostic factor for survival in patients with cancer: a systemic, quantitative review. Cancer. 2001;91:2214-2221.

8. Massa E, Madeddu C, Lusso MR, Gramignano G, Mantovani G. Evaluation of the effectiveness of treatment with erythropoietin on anemia, cognitive functioning and functions studied by comprehensive geriatric assessment in elderly cancer patients with anemia related to cancer chemotherapy. Crit Rev Oncol Hematol. 2006;57:175-182.

9. Brinks V, Hawe A, Basmeleh AH, et al. Quality of original and biosimilar epoetin products. Pharm Res. 2011;28:386-393.

10. European Generic Medicines Association. Biosimilars Handbook. 2nd ed. London: Sage; 2011.

11. European Medicines Agency. Guideline on Similar Biological Medicinal Products Containing Biotechnology-Derived Proteins as Active Substance: Non-clinical and Clinical Issues. London: EMA; 2009.

12. Michallet M, Luporsi E, Soubeyran P, et al. Biosimilars in the management of anemia secondary to chemotherapy in haematology and oncology: results of the ORHEO observational study. BMC Cancer. 2014;14:503-512.

13. Groopman JE, Itri LM. Chemotherapy-induced anemia in adults: incidence and treatment. J Nat Cancer Inst. 1999;91:1616-1634.

14. Oken MM, Creech RH, Tormey DC, et al. Toxicity and response criteria of the Eastern Cooperative Oncology Group. Am J Clin Oncol. 1982;5: 649-655.

15. Janssen-Cilag. Eprex intravenous and subcutaneous injection. 2014 Available from: http://www.janssen.com.au/files/Products/Eprex PI.pdf. Accessed September 3, 2016.

16. Cancer Research UK. Cancer incidence by age. 2014. Available from: http://www.cancerresearchuk.org/health-professional/cancer-statistics/ incidence/age\#theading-Eight. Accessed December 19, 2015.

17. Castelli R, Deliliers GL, Colombo R, Moreo G, Gallipoli P, Pantaleo G. Biosimilar epoetin in elderly patients with low-risk myelodysplastic syndromes improves anemia, quality of life, and brain function. Ann Hematol. 2014;93:1523-1529.

18. Brodszky V, Baji P, Balogh O, Pentek M. Budget impact analysis of biosimilar infliximab (CT-P13) for the treatment of rheumatoid arthritis in six Central and Eastern European countries. Eur J Health Econ. 2014; 15 Suppl 1:S65-S71.

19. Aapro M, Cornes P, Sun D, Abraham I. Comparative cost efficiency across the European G5 countries of originators and a biosimilar erythropoiesis-stimulating agent to manage chemotherapy-induced anemia in patients with cancer. Ther Adv Med Oncol. 2012;4:95-105.

20. Tzekova V, Mihaylov G, Elezovic I, Koytchev R. Therapeutic effects of epoetin zeta in the treatment of chemotherapy-induced anemia. Curr Med Res Opin. 2009;25:1689-1697.

\section{Dovepress}

patient perspectives such as quality of life, adherence and satisfaction. The manuscript management system is completely online and includes a very quick and fair peer-review system, which is all easy to use. Visit http://www.dovepress.com/testimonials.php to read real quotes from published authors. 